\title{
Justice, Recognition, and Reparations
}

Although being in the support groups already sets in place a process of attaining justice on the microlevel by way of addressing some of the harms ensuing from the sexual violations, male survivors in northern Uganda also articulate diverse exogenous justice-related needs. Yet, whereas recent years have witnessed increasing consideration for redressing conflict-related sexual and gender-based violence against women and girls, specific attention to justice for male-directed sexual violence remains remarkably absent. Indeed, despite "a pressing imperative for accountability ... that takes specific account of gender-based violence, [only] scant attention has been paid to the sexual integrity and dignity harms experienced by men" (Ní Aoláin et al. 2015: 99).

Therefore, and despite increasing efforts at the United Nations level "to ensure that transitional justice processes address the full spectrum of gender-based and sexual violence" and recognition that the "effective participation of victims ... [is] necessary to address different needs and opportunities of women, men, girls and boys" (UN 2014: 2), male survivors' justice concerns remain remarkably absent, both from the scholarly literature and postconflict programming in northern Uganda as elsewhere globally. To date, barely a handful of studies have focused on the intersections between wartime sexual violence against men and transitional justice processes, characterized by an almost exclusive emphasis on retributive means and a ubiquitous lack of empirically grounded survivors' perspectives.

This chapter homes in on this empirical puzzle and seeks to deepen an understanding of how Acholi male survivors conceptualize justice and what their respective remedy and redress priorities are. ${ }^{1}$ This investigation thereby forms part of the book's broader objective of painting a detailed and holistic analysis of the lived realities of male sexual violence survivors in northern Uganda, taking into account different aspects and phases of their lived realities, including contemporary postconflict quests for justice. To this end, the chapter discusses multiple gendered political, societal, and cultural barriers male survivors face in accessing the 
(secular) justice sector and standardized transitional justice processes in Uganda. I also analyze to what extent and how (existing and proposed) postconflict justice measures in northern Uganda respond to survivors' needs and demands, thereby evidencing a vacuum of gender-sensitive and harm-responsive justice for male sexual harms. Drawing on survivors' viewpoints and priorities, this examination thereby constitutes one of the first ever systematic and empirically guided analyses of male survivors' perspectives on justice, both in Acholiland as elsewhere globally, and so the findings presented here advance an understanding of how to deliver justice for male survivors of sexual violence, a subcategory of victims situated along the margins and peripheries of ongoing justice debates.

At the core of this chapter lies the observation that male survivors express different justice needs, which broadly center around recognition, acknowledgment, and reparations. In contrast to the often unitary focuses on international criminal accountability in redressing SGBV, including sexual violence against men, criminal prosecutions were presented as neither contemporary priorities nor feasible possibilities in the contemporary postconflict context. Instead, especially official government acknowledgment was seen to address the marginalization of survivors' largely silenced violations. At the same time, reparations, and especially material compensation and physical rehabilitation, are expected to reenable male survivors to provide for their families and thus live up to socially constructed gendered expectations and responsibilities. Based on these findings, I argue that most Acholi male sexual violence survivors seem to desire "justice as a better future" (Nickson and Braithwaite 2014: 449), in which they are able to fully participate in community life and renegotiate their previously impacted masculine identities. This requires and emphasizes the importance of a survivorcentric approach of dealing with and responding to wartime sexual violence, as included in UN Security Council Resolution 2467 and as laid out more fully in the concluding chapter.

I begin with a theoretically guided exploration of the multiplicity of meanings related to justice in contexts of transition, in general as well as context-specifically applied to northern Uganda, before presenting and systematically analyzing male survivors' empirically grounded views and perspectives on justice.

\section{UNDERSTANDING JUSTICE IN TRANSITION}

To analyze what "justice" means for male survivors of wartime sexual violence in northern Uganda, it is necessary to first establish a theorization of justice in contexts of transition. Across time and space, but especially in Western(ized) societies, justice is often understood as a shortcut for the law or for "legal," equated with judicial means at the level of institutions. Such conceptions of justice are focused on institutionalism and liberal values and "demand the presence of a sovereign state" (Sen 2017: 262). Despite the prevalence and dominance of these conceptions 
and assumptions about justice, however, scholars across disciplines, and especially in legal anthropology, have foregrounded the coexistence of multiple culturally and temporally contingent understandings of justice (Merry 1988; Nader 1965), which form the starting point for my thinking about justice.

In line with these approaches, I employ a broadened and thickened understanding of justice, recognizing "justice as an amorphous and elusive concept that can be interpreted and experienced in a myriad of ways" (Kent 2012: 33). As argued by Kent, justice "may have multiple socially embedded meanings," thus constituting a "contested concept that is constantly being negotiated within particular social and political constraints" (2012: 43). My understanding of justice, and the framework of this analysis, thus stem from the observation that there is not one universal concept of justice that can be applied across or within time and space. Rather than a distinct goal, justice thus ultimately exists more as a "notion," which "will probably never have a universal meaning" (McDonald and Allen 2015: 289). This coexistence of diverse understandings of justice can in part be attributed to the fact that demands for justice depend on individuals' prior subjective and diverse experiences and expectations, including of justice and harms. In fact, any quest and desire for justice was likely preceded by acts and episodes of injustice. At the same time, interpretations of justice are far from static but able to evolve and change across time and space.

This coexistence of multiple justice conceptions and understandings across and within societies is illustrated and captured by debates about legal pluralism and the plurality of justice systems. Legal anthropologist Sally Engle Merry defines legal pluralism as "a situation in which two or more legal [or justice] systems coexist in the same social field" (1988: 870). Legal pluralism is conventionally found where religious laws play a role in the justice system, and/or where a "legacy of colonial interaction between indigenous and European law" persists (Betts 2007: 740). According to legal anthropologists, virtually every society is legally plural in one way or another, whether or not it had a colonial past. Specifically focused on fragile or conflict-ridden societies, Anna MacDonald and Tim Allen further reiterate that globally the majority of war-affected societies are "regulated in a multifarious domain or assorted and diverse rule systems and institutions" (2015: 283), including multiple justice systems and approaches. Indeed, jurisdictional complexity and multiplicity is hardly unique, neither contemporarily nor historically.

Such is certainly the case in Acholiland, where multiple traditions of justice dating from precolonial, colonial, and postcolonial times coexist. Prior to colonization, what can broadly be referred to as different justice systems operated horizontally in that they were "regulated by a series of relationships, rather than by a state" (McDonald 2014: 71). During this period, wrongdoing and crimes were often dealt with in "open courts," which as described by Erin Baines were "held at different levels of social organization (household, sub-clan, clan, inter-clan and inter-tribal) according to the nature of the conflict (land, domestic conflict, arson, 
murder)" (2005: 16). There was indeed "not one centre of authority, but many, and their relationships were overlapping" (McDonald 2014: 71).

This plurality of justice systems in Acholiland was further intensified by the British colonial administration, which installed a form of Western legalism alongside, or rather on top of, preexisting forms of social ordering and structuring. To illustrate this imposition of Western justice ideas onto the Acholi context, the first colonial administrator of Gulu district, J. P. Postlewaith, wrote in 1947 that "we meted out justice according to our own ideas without having much real appreciation of natives' own traditions" (37). During the colonial period "the development of law as an institution, and the enforcement of a legal apparatus become a key means of social control" (MacDonald 2014: 75). As noted by Erin Baines, however, this "introduction of the court system by colonialists did not appear to wholly undermine traditional court systems" (2005: 16). Consequently, what marked this period was "the imposition of a new power system conjugated to a new legal culture" (ibid.), and traditional courts and systems of justice were slowly subordinated to a state-administered system.

In the contemporary context, this plurality of systems of authority and administering justice to an extent continues to prevail, although perhaps in a different manifestation. In present-day northern Uganda, the government's local council (LC) system coexists alongside traditional systems organized by clan and village structures. Today people and communities in Acholiland therefore engage with different justice systems, which range from informal and local, often situated within and along village and clan structures, to the official level, such as the LC system or national courts of law. The introduction of the LC system, however, significantly undermined the role and authority of elders and traditional practices, which were subjugated to state-level processes.

Although this plurality of justice systems is often attributed to colonization, in northern Uganda as indeed elsewhere globally, colonialism per se is not always solely responsible for the introduction or manifestation of legal pluralism. In fact, pluralized justice systems existed across a variety of societies and geographies prior to colonialism. While colonialism is thus not exclusively responsible for the introduction of legal pluralism as such, eurocentric and colonial approaches to justice are nevertheless at the very core of a tendency to subjugate indigenous and local justice processes. Theorizing about the plurality of justice systems is thereby characterized by a strong tendency to portray indigenous or traditional and nonstate or informal laws as necessarily subordinate to the official, state-driven, and Western form of justice. This tendency to marginalize the local and informal is particularly pronounced in transitional justice processes, as discussed in more depth below.

Overall this debate about legal pluralism shows that across and within societies, in general and in northern Uganda, plural conceptualizations of justice can coexist. Justice cannot be unanimously understood and applied, and there is sufficient conceptual and empirical ground to challenge the ubiquitous utility of one 
universally applicable and relativist conception of justice that resonates across and within time and space. This understanding is foundational to my analysis of justice in times of transition.

\section{"The Right Way Forward in the Aftermath of Wrongdoing"- Understanding Justice in Acholiland}

Resonating with these multiple justice conceptions across time and space, in northern Uganda a dominant locally contingent meaning or interpretation of justice appears to prevail. While no commonly agreed-upon translation of the word "justice" exists, the most common conception of justice in Acholi is ngol matir, which can broadly be understood as the process of determining "a right way forward in the aftermath of wrongdoing" (Porter 2013: 106). In one of the first examinations of the Acholi language, Catholic missionary Crazzolara translates ngol as "to cut," "to pass a sentence," or "to decide a question" (327), while matir can be translated as "fair" or "just." In relation to this, Holly Porter explains that "ngol matir could be understood literally as to 'cut straight,' though conceptually it is more accurate to say a fair or right judgement" (2013: 98).

Indeed, various research collaborators, for the sake of simplicity, initially translated ngol matir as "fair judgment," or "fair justice." According to this explanation, ngol matir would signify "the decision at the end of a process" (Porter 2013: 98), such as the sentencing or judgment at the end of judicial proceedings. Such an interpretation of justice, however, does not necessarily correspond with the views and priorities of most Acholis, including the lived realities of my informants, as examined below.

Crazzolara's additional interpretation of ngol as "to decide a question" in relation to justice, however, much better aligns with Acholi conceptions of justice. According to local understandings of wrongdoing and crime, primarily measured as a disruption of social harmony (Porter 2012), justice, or ngol matir-to "decide a question" - can be understood as "to decide a right way forward in the aftermath of wrongdoing" (Porter 2013: 106). In this context, "a right way forward" would ideally be determined in an inclusive and participatory process, involving survivors and offenders, and at times their wider communities, in line with restorative justice theories. In practice this is frequently done through local and traditional justice processes, as described in later parts of this chapter. What this "right way forward" must entail and how it should look, however, is often highly individual and contextual, depending on survivors' lived realities, their social context, the violations committed against them, or the identity of the perpetrator. Based upon this most common conceptualization, I thus follow Porter's approach and utilize the terminology of ngol matir for the purpose of my analysis, understood within the widened frame of "a right way forward in the aftermath of wrongdoing" (Porter 2017).

Such an interpretation of justice as a right way forward is consistent with the widened understanding of justice employed throughout legal anthropology 
scholarship, and it is much more accommodating of a variety of psychopolitical as well as socioeconomic components, elements, and processes. This approach thereby also stands in contrast to and moves beyond the institutionalized and legalistic construction of transitional justice prevalent throughout much of the literature. Such local understandings of justice vis-à-vis standardized transitional justice approaches illustrate the frictions that arise when global norms grate against local conceptions of justice. Therefore, and as summarized by Millar, "justice is not some platonic ideal, but something experienced within a context, and therefore, variable and reliant on local interpretation" (2011: 517).

\section{TRANSITIONAL JUSTICE}

Moving from a general focus on justice to a more specific examination of justice in transition after violent conflict and mass atrocities, in this section I conceptualize an understanding of transitional justice as underpinning the analysis to come. Applied to transitions after armed conflicts, dictatorship, or authoritarian regimes, justice in response to past mass violence and extensive human rights violations is commonly categorized as transitional justice, which according to the United Nations Secretary General (2014: 4) can be defined as "a full range of processes and mechanisms associated with a society's attempt to come to terms with a legacy of large-scale past abuses, in order to ensure accountability, serve justice and achieve reconciliation. These may include both judicial and non-judicial mechanisms, with different levels of international involvement (or none at all) and individual prosecutions, reparations, truth-seeking, institutional reform, vetting, and dismissals, or a combination thereof."

In referring to both judicial and nonjudicial mechanisms, the UNSG's understanding of transitional justice extends the scope of most earlier definitions, which primarily emerged from a legal standpoint and often placed a strong (if not exclusive) emphasis on judicial accountability to facilitate transitions and deliver justice at the expense of non- or quasi-judicial and noninstitutionalized processes.

By broadly working with the UN's definition, I nevertheless emphasize that the suggested catalog of prosecutions, reparations, and various other institutionalized mechanisms should be understood not as an exhaustive list but as an indication of potential measures. Instead, and depending on context, a variety of noninstitutionalized and "unrecognizable" transitional justice measures (Martin 2016) can often likewise be included. The holistic study of justice in transition should thus also entail consideration for, and a critical examination of, "everyday" practices of the way individuals and communities reconstruct their lives and rebuild relationships and societies in the aftermath of armed conflicts. Borrowing from Richmond, the "everyday" in this context refers to "a space in which local individuals and communities live and develop political strategies in their local environment. . . It is representative of the deeper local-local, 
engaging with needs, rights, custom, individual, community, agency and mobilization in political terms" (2010: 6).

In light of this evolution, Mallinder observes that "as the field of transitional justice has developed, informal approaches to justice have attracted increasing attention as a way of redressing past crimes" (2014: 4). As emphasized by Erin Baines, "Justice is a social project among many others, and the study of justice should include the various strategies employed by the war-affected populations to deal with the legacies of mass violence" (2010: 7). Instead of exclusively examining what Das and Kleinman (2001: 16) refer to as "grand narratives of forgiveness and redemption," this growing body of "remaking a world" scholarship is increasingly attentive to local and individual experiences of coming to terms with human rights abuses and transitioning out of conflict. In light of this broadened angle, I find Alcalá and Baines's broad conceptualization of transitional justice particularly helpful, as it refers to "the many individual and collective ways in which people pursue mundane activities and practices to restore the basic fabrics of meaningful social relations, negotiations or re-creative protective mechanisms and provide some sense of continuity in their lives and sense of self in relation to others in the aftermath of violence and conflict" (2012: 278).

As indicated by these definitional developments, the concept of transitional justice (TJ) thus experienced its own transition, emerging from its exceptionalist origins toward becoming a normalized, institutionalized, mainstreamed, and globalized practice. For Hansen (2014) this growth and expansion of TJ can be categorized along horizontal and vertical lines. On the one hand, justice processes are increasingly applied to diverse transitional contexts and a wide range of situations. These include not only postconflict settings or postauthoritarian and postdictatorial transitions, but increasingly also still ongoing conflict zones. Not only the points of departure, however, but also the end goals of transitional justice processes are increasingly recognized as being more diverse than initially assumed. Although in recent years TJ has been increasingly emancipated from the bonds of the paradigmatic transition, such processes are often still expected to directly promote democratization, human rights, the rule of law, and peace-building, often within neoliberal frameworks. I concur with Brandon Hamber, however, in arguing that "in reality, these processes are seldom linear, and reconstruction involves many processes that are not always captured by phrases such as peacebuilding or transitional justice" (2016: 8). Instead, the complex, unsettling, and fluid nature of transitional justice processes across time and space evidences that "dealing with the past is a continuing process, rather than confined to a specific 'transitional' period" (Kent 2012: 205).

Such is evidently the case in northern Uganda, where the Juba Peace Agreement of 2008, although not finally signed by the Lord's Resistance Army (LRA), was widely assumed to set in motion a justice and reconstruction process to be characterized by a linear transition from protracted war to liberal peace. As 
previously discussed, Uganda is a relatively diverse and comprehensive transitional justice landscape. Despite the proposal and involvement of different transitional justice mechanisms - such as the International Crimes Division (ICD), investigations by the ICC, and a draft national transitional justice policyhowever, the reality on the ground a decade later looks anything but linear; it rather reflects the messiness and ambiguity of such processes.

As part of this expansion, transitional justice has also become increasingly attentive to the gender dynamics of political transitions, including gendered harms and crimes of sexual and gender-based violence (mostly against women and girls). Even though TJ continues to have a "capture problem with gendered harms" (Ní Aoláin 2012: 20), the past two decades in particular have radically changed and further developed the treatment of gender-based violence. At the same time, however, gendered approaches to TJ are dominated by a strong focus on sexual violence and an emphasis on retributive justice and criminal prosecutions. This arguably resulted in rather limited and exclusionary gender justice developments, marginalizing quasi-judicial or noninstitutionalized justice measures and overshadowing gendered inequalities toward women as well as sexual and gender-based violence against men and boys and against individuals with diverse sexual orientations and gender identities.

The focus of the literature on prosecutorial means reflects, and has arguably been influenced by, a sustained focus on conflict-related sexual violence in the international criminal justice arena-and most notably at the International Criminal Tribunals for the former Yugoslavia (ICTY) and Rwanda (ICTR). These two ad-hoc tribunals in particular are widely credited with the responsibility for the contemporary jurisprudence on sexual violence in the context of armed conflict and are seen as having established landmark and precedence cases concerning sexual violence.

While most of the scholarly literature and most cases at the ad hoc tribunals and at the International Criminal Court (ICC) focus on gendered and sexualized violence against women, very few proceedings have involved cases of sexual violence against men, most notably so at the ICTY. The only two times that male sexual violence and rape were explicitly charged and tried under international criminal law was in the ICTY's Prosecutor v. Ranko Cesic case, and in the ICC's case against Jean Pierre Bemba in the Central African Republic, although the initial judgment in the Bemba case was appealed and overturned again in 2018. The ICC's investigation into the Kenya situation similarly included evidence suggesting that even though most crimes of sexual violence were committed against women and girls, men and boys were also affected by different forms of SGBV. Yet, and although the ICC prosecutor initially included these charges under the rubric of "other forms of sexual violence," ICC judges disagreed, arguing that the described crimes do not constitute sexual violence. According to the trial chamber, "not every act of sexual violence which targets part of the body commonly associated with sexuality 
should be considered as an act of sexual violence" (RLP 2013: 31). This limited body of jurisprudence and case law led international legal scholar Sivakumaran to attest that "the actual prosecutions of male sexual violence have been rather disappointing" (2013: 87).

At the same time, the vertical expansion of transitional justice facilitated an increasing participation and importance of local actors, including communities of victims and survivors, as well as local processes-such as grassroots measures or traditional justice rituals. What throughout the literature is described as "localizing transitional justice" thereby seeks to incorporate local norms, mechanisms, and ceremonies into TJ practice and aims to ensure that the voices, concerns, and needs of local actors and populations are integrated into these processes. The United Nations in 2004 recognized the benefits of customary local practices for larger TJ processes, by emphasizing that "due regard must be given to indigenous and informal traditions for administering justice" so that these processes can "continue their often vital role . . . in conformity with both international standards and local traditions" (18). The UN report, acknowledging the potential of locally embedded and culturally specific mechanisms, therefore emphasizes "the importance of local consultation, ownership and leadership, and recognizes the role of local mechanisms" (Anyeko et al. 2012: 110).

The growing attention to the local can largely be seen as a result of a growing disconnection between international norms and processes and local needs, priorities, and conceptions of justice. Indeed, international or national institutionalized processes are often inaccessible for conflict-affected communities, and/or disconnected from local belief systems, as well as from survivors' needs and priorities. Local customary or traditional justice systems are therefore often portrayed as better accessible and more culturally and socially legitimate for community-based or rural populations.

At the same time, however, and as noted by Shaw and Waldorf, local justice processes are primarily seen as "complements to national or international processes" (2010: 4). This implies that local justice is often treated as subordinate to processes at other levels. In the context of peace-building, developmental assistance, and transitional justice, the local is situated at the bottom of a hierarchy. A hierarchical level-based definition of the "local," Shaw and Waldorf (2010) argue, risks depoliticizing locality and "constructing it as a residual category characterized by separation [from the global, national, regional, etc.]" (6). As a result of this depoliticization, locality is often equated with the absence of modernity and is consequently downplayed in value and importance. The infantilization of the local then results in a marginalization of the experiences and perspectives of the people within this residual space, which most often constitute the vast majority of conflict-affected communities.

Traditional and localized justice processes have also taken on a prominent role in discourses and practices around dealing with the legacy of the conflict in 
northern Uganda. Different informal measures, such as the ritual of mato oput, are widely presented as locally appropriate alternatives to formalized and top-down administered means, and especially to the punitive approach of the ICC. ${ }^{2}$ Civil society representatives as well as cultural and religious leaders in particular have emerged as prominent advocates of this approach, arguing that these measures are culturally sensitive and best equipped to deal with the complex nature of the conflict and postconflict transition. In ways different from formalized processes, those mechanisms help to bring conflicting parties together with the aim of promoting reconciliation and restoration of relationships and social harmony.

Such rituals and ceremonies have a rich tradition in Acholiland. Often deeply rooted in Acholi cosmology (Gingyera-Pinycwa 1992; p'Bitek 1986), they were employed to deal primarily with interpersonal and interclan disputes. Within the context of the armed conflict and its aftermath, these traditional mechanisms were often modified and applied to deal with conflict-related harms. Nevertheless, critics have questioned the potential applicability of traditional Acholi ceremonies in dealing with mass atrocities, including with crimes of gender-based violence. On a more general level, Tim Allen (2006) raises concerns regarding the politicization of these practices, arguing that they are merely an "invention of tradition," while Branch (2008) claims that especially the practice of mato oput is affected by neocolonial interventions, especially by the quite artificially created institution Ker Kwaro Acholi (KKA) or by intervening NGOs.

A report from 2005 furthermore found that the majority of Acholi elders interviewed for the study did not think that these processes were feasible in the context of the armed conflict (Baines 2005). This potential inapplicability arises, in part, because traditional cultural beliefs and practices in northern Uganda were heavily impacted by the conflict, and in particular by widespread forced displacement. Furthermore, different rituals, such as mato oput, require the active participation of both the victim and perpetrator (and often their families/clans), which in the context of protracted armed conflict, characterized by abduction, high rates of killings, and large-scale displacement, is often difficult to achieve (Baines 2007). And lastly, during the war and in the postconflict period, "many Elders argued that poverty limited their ability to carry out rituals" (Baines 2005: 13), which requires compensational payments and the sacrifice of animals, for instance. Partly in response to these economic barriers, in recent years, different NGOs intervened to support communities in organizing these rituals, which however significantly downplayed the local agency and participation that makes these processes so unique.

\section{A Vacuum of Justice for Male Survivors in Uganda}

Despite increasing consideration for accountability for gender-based violence in general, as outlined above, little attention has been paid to justice in response to sexual violence against men. This absence of gender-sensitive and harm-responsive 
justice with utility across diverse postconflict and transitional settings is particularly evident and pronounced in northern Uganda, where previous, existing, and proposed transitional justice developments fail to account for crimes of sexual violence against men and arguably for gender-based violence more broadly.

Although the current proceedings of the ICC against former LRA commander Dominic Ongwen, and those of the domestic International Crimes Division (ICD) under the High Court of Uganda against former LRA commander Thomas Kwoyelo, include various charges of SGBV against women and girls, they do not include crimes of sexual violence against men. The investigations by the ICC's Office of the Prosecutor (OTP) to date also solely focus on crimes perpetrated by the rebel forces but not by the government army, which has been subjected to sustained criticism for one-sidedness. At the same time, the Rome Statute mandates the court to investigate crimes committed after 1 July 2002, when the statute entered into force. Since almost all crimes of sexual violence against men in Acholiland occurred during the late 1980s and early 1990s, however, the ICC cannot investigate them.

At the same time, the ICD is unlikely to be a viable avenue for male sexual violence survivors to seek justice, as it operates within the government's jurisdiction, and therefore "any prosecution of government-linked war crimes under the current government is highly unlikely" (MacDonald and Porter 2016: 703), let alone any accountability for crimes of male-directed sexual violence. To further complicate things, the Ugandan Penal Code (UPC), which forms the country's primary legal framework, also explicitly defines rape in gender-exclusive terms, solely recognizing women and girls as victims of sexual and gender-based violence and thereby explicitly excluding male survivors (see below).

The Ugandan government's draft national transitional justice policy (JLOS) further reflects these gendered blind spots. ${ }^{3}$ For instance, the policy includes only two vague references to gender and only one reference to sexual violence, thus fundamentally lacking any consideration for gendered experiences and harms, let alone any attention to male survivors specifically. ${ }^{4}$ Considering that UN women contributed to earlier drafts of the policy, this marginalization and exclusion of gender in the current version of the draft is particularly surprising.

Traditional, customary, and localized justice means, which take on a prominent role in northern Uganda, are often equally ill equipped to remedy gendered harms, including sexual violence against men. Because of their masculine and heteronormative framework, these measures are likely to ignore gendered conflict-related experiences and leave very little room to engage with masculinities outside the hegemonic norms, let alone with male sexual and gendered harms. The majority of Acholi traditional rituals also serve a different purpose, and primarily deal with killings and spiritual cleansing, making them technically inapplicable to cases of male rape. Furthermore, most rituals take place (semi)publicly on the local level, which implies that male survivors' experiences would be publicly revealed to their 
communities and families. Coupled with various other technical limitations, such as the seeming impossibility (yet technical requirement) of mostly non-Acholi perpetrator participation, these intersecting factors render traditional justice processes inappropriate and highly unlikely to potentially remedy cases of male rape.

Conditioned by these intersecting gaps, the overall transitional justice landscape in Uganda is strikingly insensitive to male survivors' sexual harms. This absence and unresponsiveness of formal processes to male sexual violence survivors and their gendered harms are further compounded by a profound Acholi lived reality of a deep-seated frustration with and mistrust of the Ugandan government to deliver justice. Echoing survivors' sentiments from across various postconflict sites, the majority of research participants in this study expressed frustration, dissatisfaction, and a lack of trust regarding state-administered or topdown elite-driven justice mechanisms. Below I further demonstrate this vacuum of gender-sensitive and harm-responsive justice by systematically evidencing the unresponsiveness of different justice measures to male sexual harms.

\section{MALE SURVIVORS' VIEWS ON JUSTICE}

Drawing on this contextual and conceptual overview of (transitional) justice developments, in northern Uganda and beyond, the remainder of this chapter homes in specifically on how Acholi male sexual violence survivors think about and understand justice in response to their sexual and gendered harms. The workshop discussions with survivors essentially foregrounded three central themes as potential avenues of attaining justice. Each characterized by a diversity of at times competing views, these themes form the framework of analysis throughout the remainder of this chapter: (1) recognition and official acknowledgment; (2) criminal prosecutions; and (3) reparations, including (a) material compensation and (b) physical rehabilitation. The analytical structure I impose in accordance with these themes represents the views expressed by the male survivors who participated in this study, how they spoke about what justice means to them, and how to achieve a sense of justice for them. What becomes evident is that these diverse justice measures are frequently linked and interdependent, thereby illustrating that transitional justice processes often need to be externally coherent. It is important to note, however, that survivors' justice-related needs are, of course, never static and potentially evolve and change over time. The analysis offered here therefore provides a snapshot into male survivors' contemporary justice conceptions and priorities.

At the core of this analysis lies the observation that despite a heterogeneity of perspectives, a consensus seems to prevail among survivors that justice processes need to directly respond to their uniquely gendered harms as a result of the sexual violations. In particular, recognition and official government acknowledgment, which can manifest in various ways, were seen to potentially address the 
marginalization of survivors' silenced violations. Reparations, and especially material compensation and physical rehabilitation, are further expected to reenable male survivors to provide for their families and thus live up to socially constructed gendered expectations and responsibilities. Based on these findings, I argue that most Acholi male sexual violence survivors seem to desire "justice as a better future" (Nickson and Braithwaite 2014: 449), in which they are able to regain a minimally functioning life, fully participate in community activities, and renegotiate their impacted masculine identities. Male survivors' views on and preferences of justice thereby follow anthropologist Veena Das, who has explored how processes of social reconstruction are often enacted through not only "some grand project of recovery," but also through the enactment of "everyday tasks of surviving" - including being able to do the work of the everyday (Das 2000: 222). Drawing on this groundbreaking work by Veena Das, Gray, Stern, and Dolan call for processes of attaining justice and social repair in the aftermath of violence that are "centrally and unavoidably social," not undertaken by "an autonomous subject as imagined by liberal theory, but rather by a socially embedded and relational subject" (2019: 8) - and thus in line with the broader, relational understanding of justice put forward above.

\section{Government Acknowledgment: "To me, justice means recognizing suffering"}

To begin with, wider recognition and in particular official government acknowledgment constitute prime justice needs for the majority of male survivors who participated in this study. While in the previous chapter, I discussed how support groups enable survivors to strive for wider societal recognition, and how this links to recognition-theoretical conceptions of justice, here I focus primarily on acknowledgment by the government in line with survivors' viewpoints.

In both theoretical and practical terms, recognition and acknowledgment can be seen as inherently linked. This is locally reflected in linguistic and cultural terms: In the Acholi language, acknowledgment translates as niyee, and recognition is translated as moko niyee, confirming acknowledgment. Recognition and acknowledgment are thus viewed as distinct yet fundamentally linked, and (full) recognition can depend upon acknowledgment. In the context of this study, and as articulated by survivors, acknowledgment primarily must be official, issued by individual and/or institutional perpetrators, whereas recognition can be offered more widely and on a societal level, not exclusively dependent upon the perpetrators' involvement.

Throughout the transitional justice literature, official and/or perpetrator acknowledgment is often regarded as a key component of delivering justice, linked to a variety of different transitional justice measures, including reparations. Wendy Lambourne, for instance, argues that "having perpetrators acknowledge what they have done and its impact on victims can be crucial for justice," highlighting "the 
need for acknowledgment as an important part of transitional justice" (2009: 41). Approaching acknowledgment more from a psychological perspective, Shnabel and Ulrich similarly elaborate that for justice, "victims are likely to want perpetrators to acknowledge their responsibility for the injustice they have caused" (2013: 117). And for de Greiff (2008), "acknowledgment is important precisely because it constitutes a form of recognizing the significance and value of persons" (14), and primarily of their victimization.

Mirroring these conceptual reflections, according to male sexual violence survivors in Acholiland, "justice is when the government acknowledges what happened to us." Various service providers working with male survivors in interviews with me similarly emphasized that "in terms of justice, acknowledgment by the government of the violations is crucial." The survivors who participated in this study thus primarily demand official, institutional acknowledgment by the government responsible for commanding and perpetrating these crimes. Interestingly, survivors spoke less prominently about acknowledgment by individual perpetrating soldiers, seemingly recognizing the government army's collective command responsibility.

For the majority of survivors, government acknowledgment must ideally be manifested through official statements and/or apologies. The chairperson of one the three subgroups affirmed that "to acknowledge the crimes, the government should give an apology," while another male survivor similarly stated that "there needs to be acknowledgment in the form of an apology." This need for official acknowledgment for harms suffered by the civilian population during the conflict is not exclusive to male sexual violence survivors, as victims across the conflict-affected north demand government acknowledgment for the crimes committed against them. What is unique about male sexual violence survivors' quests for government acknowledgment, however, is that these crimes remain particularly silenced, marginalized, and ignored compared with other violations. One survivor declared that "the government should come out and acknowledge what they did. . . . In most cases, when there are big meetings, we are not recognized, but they go into recognizing other vulnerable groups of people, like the disabled, the widows, the orphans. What about us? We don't have any voice, and that will only change if the government acknowledges what happened to us."

Whereas a whole catalog of conflict-related human rights violations, including government perpetrated abuses, is increasingly brought to the forefront within the contemporary transitional context and is even partially acknowledged by the government, crimes of male-directed sexual violence continue to remain marginalized and silenced. 5 We recall that in Acholiland's hetero-patriarchal society, the rape of men is largely unacknowledged or considered not possible to have occurred. In light of this lack of affirmation, male survivors want their experiences officially acknowledged and thereby validated. 
For numerous survivors, acknowledgment is furthermore regarded as a crucial precondition for accessing other remedies, responses, and, importantly, reparations, further demonstrating the interconnections among different justice-related measures. For instance, one survivor emphasized the importance of acknowledgment as a first step to access reparations, by explaining that for me, the government ... needs to acknowledge what happened. What will the government do if it fails to acknowledge the acts of sexual violations in Acholiland? For the government to do something, and to, for instance, pay us compensation, they first need to acknowledge that they did this to us, and then that would also be justice."

Various survivors indeed articulated that acknowledgment is relevant and valuable only if followed by reparations, and vice versa, reparations can only be meaningful if they are provided as a means of acknowledging the specific sexual violations and survivors' harms: "If there is compensation that means there is full acknowledgment. If it stays with just acknowledging without keeping the promise and paying, that is not real acknowledgment." Such concerns align with conceptual and empirical observations that victims often criticize public apologies of acknowledgment "as being empty words if these apologies are not accompanied by reparations" (Llewellyn and Philpott 2014: 6). Acknowledgment itself would thus not be sufficient but would have to be accompanied by additional measures, such as compensation, thereby supporting Hamber and Wilson's argument that "for most people, more is needed than simple recognition and acknowledgment" (2003: 43).

Obtaining government acknowledgment for crimes committed by state forces, however, is fraught with inherent cultural, social and political challenges, further exacerbated by the gendered dimensions of the violations within a heteropatriarchal context. "The government will not acknowledge this because it happened long ago and they were the ones perpetrating it, so they will not recognize and respond," one male survivor attested. Another survivor similarly stated that "acknowledgment is very important for us, but the biggest challenge . . . is how do we propel the government to acknowledge the wrongs committed against us? We do not have any clear way of convincing the government to do that. That is why everything lies in the hands of the government."

These concerns suggest a deep-seated frustration over the profound lack of measures and provisions by the government for male survivors, including a lack of affirmation of their experiences. On a more general level, when state forces have been involved in perpetrating human rights violations, official acknowledgment may often materialize only after regime changes. Indeed, when the power structures that are responsible for widespread human rights abuses are also in charge of designing and implementing national and top-down justice measures, government-perpetrated crimes almost inevitably fall off the radar. We recall that in northern Uganda the government from which survivors demand 
acknowledgment is the same regime that was responsible for the perpetration of sexual violence against men more than twenty-five years ago. Among the conflictaffected community in Acholiland at large, a widespread belief prevails that without a regime change, there will be no accountability for NRA atrocities.

In addition to these political barriers, acknowledgment for sexual crimes against men is specifically characterized by a variety of gendered, social, and cultural challenges and therefore seems particularly elusive. In Acholiland's heteronormative and patriarchal setting, male vulnerability is regarded as incompatible with hegemonic masculinities (chapter 4), and male sexual abuse is perceived as de facto nonexistent. Conditioned by the social stigmatization attached to male rape, some survivors themselves previously and currently do not want their experiences of abuse publicly known or recognized. Furthermore, publicized acknowledgment of male sexual victimization can carry wide-reaching psychosocial consequences for survivors and can imply the risk that male survivors face social stigmatization from their families and communities, or that they can be criminalized for samesex acts, which are punishable by life in prison in Uganda. This unveils a seeming paradox: Male survivors demand acknowledgment for their marginalized and silenced experiences despite the risk that (public) awareness may cause stigmatization, leading to social and psychological harms. Therefore, many survivors want the government to acknowledge the widespread perpetration of these crimes in general but without necessarily publicly revealing survivors' identities.

At the same time informal ways to acknowledge and memorialize the suffering of survivors exist. These include, for instance, communal and local monuments and memorials, which in a broader sense can be classified as symbolic reparations. In northern Uganda community-led monuments and memorials constitute common ways of remembering conflict-related experiences and atrocities across Acholiland. For instance, according to a population-based survey on attitudes about justice, almost all (95 percent) "of the respondents said they wanted memorials to be established to remember what happened in Northern Uganda" (Pham et al. 2007: 34). To some extent, these sentiments for community-based memorialization also resonate with male survivors' conceptions. Indeed, since the government has not acknowledged any responsibility for the perpetration of male rape, some survivors also seek other forms of recognition. According to one male survivor, "If you have everything but no memorial, there will be no justice. If a memorial is not there, ... there is no acknowledgment and recognition."

Across Acholiland, a variety of community-based memorialization initiatives exist, including at least one memorial that includes acknowledgment of male rape. In 2015 the community of Burcoro in Awach subcounty, where male rape was particularly widespread, received logistical and financial assistance from the Justice and Reconciliation Project (JRP) to erect a monument in memory of a 1991 NRA-executed massacre that included acts of tek-gungu. The memorial structure is in the shape of a tree-since one of the massacre victims was tied to a tree and 


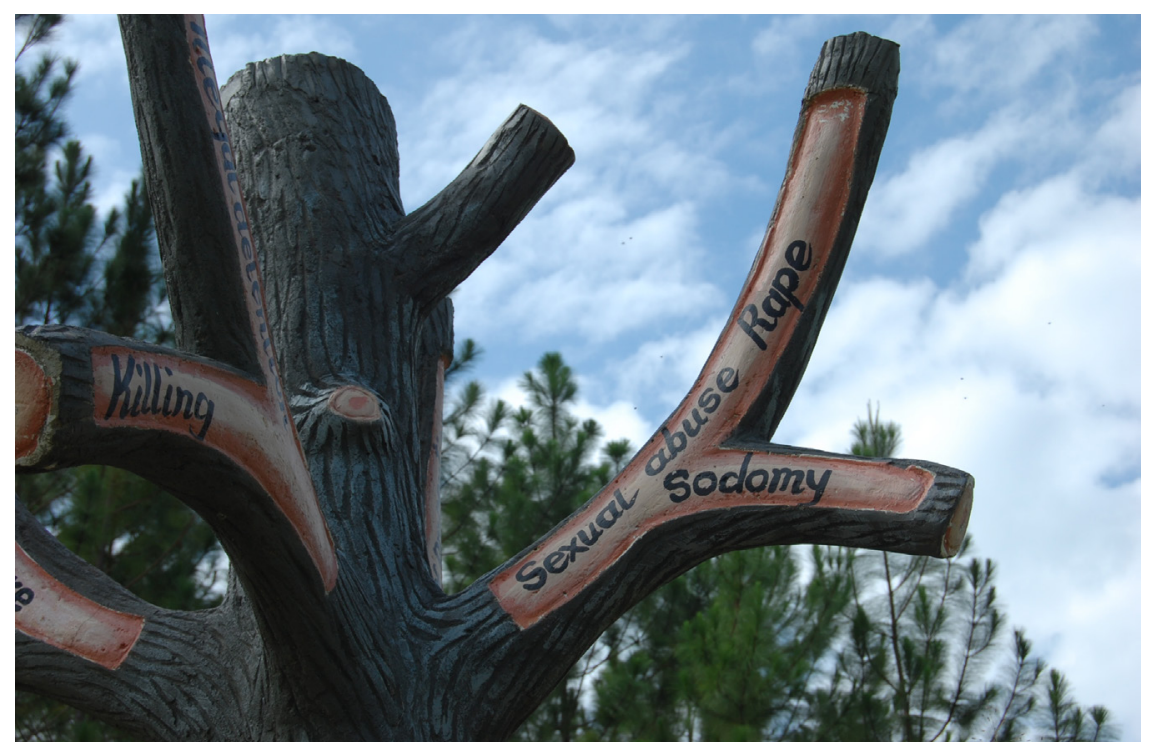

FIGURE 3. Monument in Burcoro, Awach subcounty.

executed by a firing squad - and is located at the former execution spot. A variety of human rights abuses and crimes perpetrated during the massacre, such as killings and acts of torture, are marked on the different branches of the tree. One of the branches, clearly visible to everyone who inspects the monument from the front, reminds the viewer of crimes of "sexual abuse," "rape," as well as "sodomy," which is how male rape is often referred to in English across the region.

For many male survivors from Burcoro, this monument and its specific mentioning of sexual violence against men is an important aspect of recognizing their experiences and thus obtaining justice, even though it is not a form of official government acknowledgment. Such a localized memorialization initiative cannot replace government acknowledgment, but it can function in addition and complementary to official state recognition. These informal memorials ultimately serve a purpose different from official government acknowledgment and memorialization efforts: They strive to make visible the communities' recognition of sexual violence against men and demonstrate that male sexual violence survivors should be treated equally to victims of other conflict-related experiences. Therefore, in a context where male sexual violence survivors are marginalized and silenced, communitybased memorialization of male-directed sexual violence can carry its own particular value and importance, for the community as well as specifically for survivors.

\section{Criminal Justice and Prosecutions}

Criminal prosecutions were another prominent justice-related theme that emerged during the workshop discussions with the survivors. Ultimately survivors' 
perspectives on criminal justice and prosecutions vary: While some viewed criminal proceedings as potential avenues for attaining justice, most survivors expressed a fundamental mistrust in the criminal justice system and did not view prosecutions to be feasible or necessarily desirable in the current social and political context. Conditioned by the seeming impossibility of prosecutions for redressing male sexual abuse, criminal justice therefore does not seem to be a current priority for the majority of survivors in this study. Male survivors' views thus tend to stand in contrast to the legalistic orientation of the global transitional justice project, which continues to present criminal prosecutions as the benchmark from which other justice processes merely follow. This privileging of legalistic measures specifically characterizes the growing body of scholarship on SGBV accountability in general and the admittedly limited literature on sexual violence against men and transitional justice in particular (see Schulz 2015, 2020a).

Yet despite these dominant sentiments, some survivors do believe that criminal prosecutions are potential avenues for attaining justice. One survivor stated plainly, "I want the issue [the crimes] to be taken to court, because if the discussion is pushed to court, I would see justice," while another said that "to me, justice is fighting impunity." Interestingly, however, survivors seemed not to prefer trials as a means of retribution. During the workshops no male survivor explicitly expressed a desire for criminal accountability and punishment of the perpetrators out of retributive motives. Similarly, other prominent and commonplace objectives of (international) criminal justice, such as deterrence and the investigation of command responsibilities to identify wider patterns of crime and violence, were not raised by survivors as desired outcomes of prosecutorial processes. Apart from one exception of a survivor for whom prosecutions "can block the continuation of the same problem [of male rape]," survivors did not specifically emphasize deterrence, for instance, as a desired outcome of criminal prosecutions.

Instead, several survivors explicitly raised prosecutions as avenues to materialize acknowledgment and to access reparations. One male survivor attested that "if we take this to court, it means our violations are acknowledged at the official level, and we will also be able to get reparations." Another survivor suggested that "we first ask the government to acknowledge and then compensate. If they do not agree, we need to take them to court to get the acknowledgment and compensation through the courts." Further illustrating these perceptions of prosecutions as avenues to obtain acknowledgment and reparations, another male survivor stated that "justice is when the government will be taken to court and acknowledge what happened to us." Although retributive justice theorists have emphasized that criminal proceedings can contribute to acknowledging victims' suffering as a crucial ingredient of delivering justice, recognition is nevertheless seen as only a byproduct of criminal prosecutions rather than its primary objective. For many male survivors in northern Uganda, however, it appears that official acknowledgment through the courts constitute a primary desired outcome of judicial proceedings. 
At the same time, and despite these rather isolated positive views on criminal justice, the majority of survivors indeed expressed skepticism and negative perceptions regarding prosecutions. These attitudes particularly concern the feasibility of criminal proceedings, conditioned by various legal, social, cultural, and political barriers, many of which are heavily gendered. This lack of faith in the criminal justice system consequently implies that prosecutions do not constitute a contemporary priority for most male survivors. This may likely be the case because prosecutions would not directly address survivors' postconflict needs. Instead of retrospectively criminalizing perpetrators, survivors prioritize processes that help them in their current situation, such as rehabilitative assistance and a return to "normality" through reparations.

Many survivors were well aware of the technical limitations of the legal protection and coverage of male survivors by Ugandan law. During a discussion about prosecutions and the national justice system, one survivor noted that "the law does not prohibit male rape. We may want to take it to court, but we cannot because of the law." In fact, the Ugandan Penal Code defines rape in gender-exclusive and essentializing terms as affecting women only: "Any person who has unlawful carnal knowledge of a woman or girl, without her consent, or with her consent, if the consent is obtained by force or by means of threats or intimidation of any kind or by fear of bodily harm, or by means of false representations as to the nature of the act, or in the case of a married woman, by personating her husband, commits the felony termed rape (Ugandan Penal Code Act 1998, chapter 14, section 123: 56, emphasis added).

This systematic exclusion of male survivors from legal protection is neither atypical nor exclusive to men in northern Uganda. According to research by Chris Dolan and RLP, "9o per cent of men in conflict-affected countries are in situations where the law provides no [or only inadequate] protection for them if they become victims of sexual violence" (Dolan 2014: 6).

In addition to this lack of legal coverage, Uganda's criminalization of homosexuality further renders the prospects of justice through the court system for Acholi male rape survivors to be very unlikely. When homosexuality is outlawed and criminalized, reporting crimes of male sexual violence, which in northern Uganda are often equated with homosexuality, can lead to incriminations and prosecutions of survivors themselves. Many survivors worried that if they officially reported the crimes to the police, they would be accused of homosexuality, and hence mostly chose not to report the violations. In addition to illuminating these very real disincentives for male survivors to judicially report the sexual violations committed against them, this also shows that the judicial exclusion of male sexual violence victims is not only composed of legal layers, but is also intrinsically linked to and compounded by informal, socially based gendered beliefs.

Besides these technical and gendered barriers of the formal justice system, there are immediate political restrictions when it comes to prosecutions. Many 
male survivors noted security constraints in relation to attempts to use judicial means against the current regime responsible for the perpetration of these crimes: "Taking the government to court also implies security issues and risks. And it is of course difficult to take the sitting government to court," one male survivor noted.

Similarly, when the state apparatus tasked with delivering justice through the national system is responsible for crimes for which redress and accountability are sought, survivors often do not expect legal justice to be served and eventually give up their hopes for retribution. In such contexts, survivors often decide not to pursue criminal cases through the official system and instead turn to alternative approaches that may be preferred for accessibility and harm-responsiveness. The fact that the identities of most perpetrators, or of those who commanded these crimes, remain unknown to the survivors further complicates the prospects for prosecutions. As summarized by one survivor, "The perpetrators of this violence are majorly non-Acholis. We do not know them, we do not know where they are, and whether they are still alive, and if we want to prosecute, whom do we prosecute? Whom do we put our complaints against? We don't know."

These concerns about the seeming impossibilities of judicial justice through the court system must further be contextualized within a wider Acholi lived reality of "a deep distrust of higher authorities to dispense justice in their interest" (Porter 2012: 81). Many Acholis, including the vast majority of male survivors, have lost faith in these formal systems and ways of dispensing justice. Various survivor statements illustrate this distrust: "For me I know that with this government, if you take this issue [of the sexual violation] to court, there will be no justice," one male survivor proclaimed. Another survivor similarly expressed his general dissatisfaction with the system by stating that in general, "court issues delay a lot in this country." Most likely because of the legal constraints of the ICC's mandate in this context and the distant form of justice it symbolizes, the court in The Hague was not once mentioned by survivors during the discussions.

The combination of these intersecting factors-the lack of coverage and protection from the law, the criminalization of homosexuality, security constraints, and the seeming impossibility of prosecuting the sitting government, coupled with deeply rooted mistrust in the Ugandan justice system as well as gendered societal beliefs and practices-render the prospect for prosecutions in this context highly unlikely. Conditioned by these challenges and limitations, prosecutions thus appear not to constitute a priority for most male sexual violence survivors in northern Uganda.

\section{Gender-Sensitive Reparations}

Instead, for the majority of survivors, reparations in response to their sexual and gendered harms constitute a fundamental component of justice. Male survivors' perspectives thereby reflect the centrality of compensation to Acholi conceptions of justice more broadly. Although diverse, survivors' views on reparations primarily 
focus on two elements: material compensation and physical rehabilitation. Drawing on these views, it becomes evident that reparations, and in particular material compensation and rehabilitation, can constitute harm-centric and gender-sensitive justice mechanisms in response to male sexual violence.

Reparations are often classified as among the most victim-centric transitional justice mechanisms, and a growing body of scholarship focuses on reparations. In practice and implementation, reparations can broadly include restitution, compensation, rehabilitation (including access to medical and psychological care), satisfaction, and guarantees of nonrepetition. In postwar northern Uganda and the state level, both the Juba Agreement on Accountability and Reconciliation (AAR) and the draft transitional justice policy include proposals for a holistic reparations program. Thus far, however, since the policy has not yet been legislated, a reparations program has neither been designed nor implemented, and survivors across the subregion continuously express frustration and dissatisfaction over the lack of reparative measures. At the same time the TJ policy, including its reparations framework, is characterized by a striking absence of any sustained consideration for gender, let alone any mention of sexual violence survivors, neither male nor female.

These gendered blind spots in Uganda reflect practical and "conceptual gaps in the legal and policy framework for reparations addressing conflict-related sexual violence” globally (Ní Aoláin, O’Rourke, and Swaine 2015: 97). As noted by Ní Aoláin et al., any remedies for conflict-related sexual violence, including reparations, "must be sensitive, flexible, and encapsulate gender-appropriate approaches" (2015: 110). However, while increasing attention is paid to women's experiences and female sexual violence survivors in relation to gendered reparations (RubioMarin 2009; Walker 2016; Duggan et al,. 2008), albeit characterized by various limitations and restrictions (Rubio-Marin and de Greiff 2007), "tailored intervention to address male-centred sexual harms remains elusive and marginalized" (Ní Aoláin, O’Rourke, and Swaine 2015: 109). As a result, “a limited understanding of who can be a victim of sexual harms means that violence against men is often unseen and unaccounted for when states and other international actors conceive and implement reparations" (ibid.: 97).

Despite this national and global unresponsiveness of reparations programs to male sexual harms, the majority of male survivors who participated in this study expressed strong demands for reparative measures in the form of material compensation, including most prominently the provision of agricultural tools, as well as physical rehabilitation, rather than monetary compensation. These means were expected to help survivors in their current socioeconomic situation and thereby immediately respond to their gendered harms. Such compensation measures also reflect reparations types commonly included in traditional Acholi justice processes, which are "largely paid in the form of livestock" (Baines 2005: 15). For instance, one survivor emphasized that "for justice we can ask the government 
to provide reparations to us, if it is in terms of restocking [of livestock], it would be a source of livelihood, and that is what I will wipe my tears with. And if it is monetary, I will also use the money appropriately knowing that it comes from my violent background."

As articulated by another survivor, "Now that I am weak, the government could compensate me with oxen or ox ploughs to dig and to allow me to sell stuff and support the children." Another survivor said that "we should be supported and compensated; for example animals should be given to us, to be kept for us, or oxen for work to access and plough the land."

According to these viewpoints, providing male survivors with agricultural tools and other material provisions is expected to help them move on with their lives by elevating them (back) into a position in which they can (again) provide for their families. As discussed in chapter 4, the sexual violations and the resulting physical and psychological consequences and harms prevented the majority of male survivors from providing for their families, as they are socially expected to as men and according to hegemonic masculinity constructions. In response to these harms, and through the provision of material compensation, various survivors hope to be reenabled to engage in agricultural activities or manual labor, thereby returning to a sense of normality through everyday practices. From the perspectives of male survivors, material compensation would thus allow them to build a better future for themselves. Compensation would therefore be about "justice as a better future."

Male survivors' longing to be restored to their physical and psychological states prior to the harms resonates with Rubio-Marin and de Greiff's (2007) conception of gender-sensitive reparations, which must broadly aim to "rehabilitate victims, to improve their quality of life or, at the least, to optimize their chances of recovering a minimally functional life" (331). In this capacity, the provision of material compensation would be a gender-sensitive and harm-responsive form of reparation.

On a critical note, however, and similar to the dynamics of repairing gender identities discussed in relation to the victims' groups (see chapter 5), this sense of "normality" from the perspectives of men can potentially translate into an unequal status quo ante, characterized by male prestige and patriarchal privilege. As introduced in the previous chapter, MacKenzie and Foster theorize these dynamics as "masculinity nostalgia" - referring to "a romanticized 'return to normal' that included men as heads of household, economic breadwinners, primary decision-makers and sovereigns of the family" (2017: 15). In this reading, justice is perceived to be attained if survivors' sense of hegemonic masculinity within a hetero-patriarchal gender ordering is reconstituted. Quests for stability, security, and justice, however, inevitably remain fraught if "dependent on, or intertwined with, a commitment to restoring oppressive gender norms" (MacKenzie and Foster 2017: 15). Therefore, caution is required so that gender-sensitive and harm-responsive reparations do not only repair the previous unequal status quo but rather set in 
place processes of shaping new and potentially more egalitarian gender identities and relations.

Other demands for compensation included proposals to construct health centers and schools in the areas where the survivors live so that their families and communities could benefit. In line with these sentiments, a variety of male survivors also asked for their families to be helped with the payment of school fees. A 2015 study of survivors' experiences of sexual violence in northern Uganda found that the inability to pay school fees constitutes one of the greatest challenges for female and male survivors of gender-based violence alike (Apiyo and McClain Opiyo 2015). Such demands for education fees and communal schools or health centers express survivors' concerns that the government "must not only compensate us but also our families." Summarizing these considerations, one male survivor asserted that "we have all become very weak, and if justice is to prevail, then they should look at the children that we have and support them, for instance in school, because we don't have the ability and energy anymore to do anything to change the lives of these children."

Because many male survivors are now elderly, their postconflict justice-related needs thus extend to redressing not only their harms but also to assisting and supporting their families' needs, evidencing the horizontal and vertical ripple effects of gendered harms and of postconflict justice processes.

Furthermore, for the vast majority of male survivors, compensation is regarded as a meaningful component of justice only if accompanied by, or delivered as a form of, acknowledgment and recognition. As articulated by one survivor, "Reparations are only a way of justice if they come with acknowledgment by the government," a normative position taken by the majority of survivors who participated in the study. According to male survivors' views, reparations thus also have an important symbolic dimension by demonstrating "signs of recognition of victims as ... equal citizens" (Rubio-Marin and de Greiff 2007: 331). At the same time, and comparable to survivors' views on prosecutions, various respondents expressed skepticism concerning the prospects of receiving compensation. Given the absence of a comprehensive reparation scheme and the lack of any consideration for gendered experiences and especially male-directed sexual violence in the national TJ policy, the prospect for compensation appears particularly remote.

\section{Physical Rehabilitation}

In addition to material compensation, rehabilitation constitutes another justicerelated priority for many male survivors. As defined by Pablo de Greiff, rehabilitation broadly "refers to measures that provide social, medical and psychological care" (2008: 3 ) to victims of violence and armed conflict.

During our workshop discussions, various survivors affirmed that "if there is any kind of physical rehabilitation, that would definitely be a form of redress." According to one male survivor, "My major justice need is rehabilitation. So when 
I am physically rehabilitated, I will get healing and strength, and I will get a normal life like any other community member." This emphasis on hoping to obtain a normal life like any other community member is important for understanding this notion of justice through rehabilitation. These concerns are thus closely linked to a return to the ordinary in the aftermath of human rights violations. In male survivors' perspectives, physical rehabilitation - through, for instance, medical treatment and psychological assistance-implies the potential to transform and restore their physical abilities, including to conduct physical labor. Rehabilitation is thus expected to reenable survivors to provide for their families and live up to gendered societal expectations, aligning with their views on reparations more broadly. Summarizing these concerns in relation to justice, one male survivor explained "I have no energy to dig so I am thinking that if we could get treatment and rehabilitation for the health problems, that would be justice."

Similar to material compensation, physical rehabilitation would thus enable survivors to reestablish a sense of normality in a transformative sense. Koloma Beck (2012) explains that "normality refers to the social processes in which the structures of the everyday environment are established, reproduced and negotiated" (53). For Martin (2016), the frame of normality is an "important concept to engage with in postconflict contexts" (401). In Sierra Leone, for instance, many survivors "were able to find peace and justice by regaining a sense of normality and were able to do this through everyday practices" (ibid.). Tapping into this growing debate about the everydayness of remaking a world and of attaining justice, the analysis here shows that physical rehabilitation can enable male survivors in northern Uganda to (re)gain this sense of normality, thus fundamentally constituting the "right way forward in the aftermath of violence" in a broadened sense of justice and in a gender-sensitive and harm-reactive manner. At the same time, however, and as critiqued above, these processes risk reestablishing patriarchal gender hierarchies by reinstalling men as primary providers and thus elevating them back into positions of dominance and power.

In northern Uganda's vacuum of state-administered measures, various service providers, including the Refugee Law Project, offer different rehabilitation measures for war victims. Under their now phased-out Beyond Juba Project (BJP), RLP provided psychological services and physical rehabilitation measures for a variety of conflict-affected communities across Acholiland, including male sexual violence survivors. As a result of these efforts, numerous survivors in the groups also received counseling to begin a process of addressing the psychological dimensions of their harms. Various male survivors were also referred for medical treatment to Saint Mary's Hospital in Lacor, just outside Gulu town, to attend to their physical injuries as a result of rape. These steps responded to some of the most severe harms experienced by male survivors.

For some of the survivors who received physical rehabilitation under RLP's project, in the absence of state-driven reparations, these measures constituted a 
form of redress and a component of justice. Various survivors who received physical rehabilitative support explicitly attested that its outcome helped them to renegotiate their masculine identities. "Through the medical treatment, I was able to work again and provide for my family like a man," one male survivor stated. Other survivors who advocated for rehabilitation, but have not yet received any assistance, likewise confirmed that such measures could constitute an aspect of justice, which would help them to renegotiate their masculine selves.

At the same time, however, for another sizable group of survivors, physical rehabilitation does not suffice as a form of justice if provided by RLP, humanitarian agencies, or nonstate actors because it crucially lacks the government acknowledgment component. According to these perspectives, "rehabilitating us should have been the responsibility of the government who committed these crimes. It is goodwill if RLP helps us with these measures, but not the sign of justice. When the government would come and say that they did something to me and that they help me now with rehabilitation, then that is justice to me."

Therefore, for various survivors physical rehabilitation has to be provided by the government for it to be a form of justice, and it needs to be accompanied by (while in itself symbolizing a form of) official acknowledgment. If provided by nongovernmental actors, these forms of rehabilitation would rather qualify as development work rather than justice. Despite once again illustrating a variety of divergent perceptions, such views accentuate the centrality of government acknowledgment for survivors and its connections to prosecutions, compensation, and rehabilitation.

Yet while the majority of male survivors view reparations positively, a small minority of survivors who participated in this study also represented an opposing viewpoint (see Schulz 2018c for a detailed analysis of this viewpoint). According to this perspective, compensational payments were considered as a form of dowry, locally conceptualized as luk (see Porter 2017), to be paid to the survivors by the perpetrating government. In this reading, reparations, if regarded as $l u k$, risk further cementing survivors' perceived gendered subordination as previously initiated through the sexual violations. If viewed as dowry, reparations can thus further entrench gendered harms rather than redressing suffering and vulnerabilities, as they are typically theorized to, carrying important implications for the intersections of reparations, victimhood, and gender. This viewpoint also demonstrates that reparations (and perceptions thereof) are value loaded and inevitably depend on local gendered, cultural, and societal contexts, as well as conflict-affected communities' locally specific and subjective interpretations.

\section{IMPLICATIONS FOR SEXUAL VIOLENCE AND JUSTICE}

Survivors' views on justice are thus evidently characterized by a diversity of at times competing views. For instance, whereas some survivors regard prosecutions 
as avenues for delivering justice, others do not see retributive means as a priority. Likewise, some survivors view physical rehabilitation provided by nonstate actors as contributing to justice, while others consider that rehabilitative measures can constitute justice only if linked to official government acknowledgment.

This variety of perspectives among survivors should not be surprising, and it has previously been documented in northern Uganda as well as elsewhere globally. The examples offered here thus contribute to this awareness and illustrate the individuality of postconflict needs among conflict-affected communities, including justice-related concerns. At the same time, and despite increasing awareness, it appears that this realization - that justice needs are often highly individual and differ among survivors - has not yet been fully integrated into transitional justice scholarship and practice, especially in the legalistically and institutionally dominated literature. When it comes to survivors' perceptions and priorities of justice, gross generalizations are frequently made about how to deliver justice for everyone. In the specific context of redressing sexual violence against men, strong and unquestioned assumptions prevail that legalistic and institutionalized measures are needed to deliver justice. The analysis presented here confirms instead that justice-related needs and perspectives are essentially products of culture, cosmology, sociality, and gender within each local context, and are therefore highly local in nature.

Survivors' needs therefore cannot easily be transferred to other conflicts or be generalized across and within cases. In her influential book Settling Accounts Revisited, Diane Orentlicher (2007) questions those kinds of generalizations: "Given the extraordinary range of experiences and cultures, how could anyone imagine there to be a universally relevant formula for transitional justice?" (18). The example of the survivors for whom compensation would be a form of dowry illustrates these cultural and cosmological contingencies of justice needs. In addition to these contextual specificities, the findings presented here specifically illuminate that survivors' views on justice processes are not even necessarily unified among survivors of a specific violation within one particular case. Rather, individual survivors' needs within one particular social and geographical locality often vary, shaped by survivors' micro-, mezzo-, and macro-environments. As convincingly argued by Cullinan (2001), "Generalised and conventionally summarised victims' expectations tend to denigrate the complex and inconsistent human identity of such victims and survivors, ignoring the extent to which needs vary from victim to victim and change across time" (19). This individuality of justice needs among conflictaffected communities inevitably raises the complex conceptual and empirical question of how to articulate broad claims in transitional and postconflict settings and thus carries broader implications beyond this case.

Institutionalized, top-down transitional justice processes, which dominate practices of dealing with the past-such as the JLOS-administered draft transitional justice policy in northern Uganda and the ICC's intervention on the African 
continent more widely-are ill-equipped to take into account this individuality, thereby frequently doing a great disservice to survivors and their individual quests for justice. In light of this, I emphasize that prescriptive, mimetic, and elite-driven top-down approaches to transition must be complemented with processes that foster survivors' agency and are participatory and bottom-up. At the same time, official processes need to be designed in more flexible ways that accommodate survivors' voices and allow preferences to be incorporated into the design and implementation. The recognition of survivors' groups as a potential avenue for delivering justice in transition (chapter 5 ) is a first step in this direction.

These findings similarly emphasize the importance of consulting survivors about their justice needs and demands before designing and implementing postconflict justice processes. The centrality of victim participation and consultations for transitional justice processes has previously been recognized in scholarship and practice alike. The United Nations (2014), for instance, emphasizes the importance of effectively consulting victims about their perspectives on postconflict justice. Despite increasing recognition of the importance of victim inclusion and participation, however, sustained engagement with victim constituencies still does not constitute an established practice for most transitional justice processes globally. Across time and space, the vast majority of transitional justice mechanisms continues to be top-down and are rarely driven, mandated, or influenced by victims' perspectives. Male sexual violence survivors have thus far not at all been considered by any such contexts globally.

In northern Uganda the draft transitional justice policy likewise recognizes the importance of victim consultations and in part claims to have done so. But these efforts were limited and insufficient and at most engaged very small and nonrepresentative parts of the population. Victim communities often express frustration over the lack of consultation, attesting that their views have not been sufficiently recorded. Prior to this study, Acholi male survivors of sexual violence in particular were net yet properly consulted about their viewpoints on justice either by relevant (national or international) transitional justice policy-makers or by researchers, thus evidencing the marginalization of male survivors' harms and experiences. At the same time, victim consultations carried out under the auspices of the government responsible for grave human rights violations itself cannot be expected to realistically capture survivors' honest views on justice, in particular relating to redress for state-perpetrated crimes. To ensure that the voices, perspectives, and needs of a broader range of victims are effectively captured, and to work toward meaningful and genuine consultations, such efforts have to be geographically widespread and large scale, ideally carried out by independent (often nonstate) actors.

Scholars, policy-makers, and transitional justice practitioners would surely highlight the difficulties (and seeming impossibilities) of consulting each conflictaffected individual in a particular locality about their justice-related needs and preferences, including the challenges of being able to respond to these individually. 
Being aware of and sympathizing with these challenges, however, I nevertheless stress the importance of victim consultations, including studies like this, which are underpinned by the viewpoints of survivors. In concert with others, I emphasize the importance of evidence-based transitional justice and therefore urge transitional justice scholars and practitioners to better engage in dialogues, for programs to be based on consultations, data, and evidence, and for researchers to more openly and transparently communicate their findings beyond pay-walled journals accessible only within the academy. Arguably, and without wanting to give the work at hand too much credit, open access publications like this book may be a first and important step in that direction.

These different paradoxes illustrate one of the tragic realities of transitional justice: The apparent insufficiency of generic postconflict and transitional responses is frequently matched by a seeming impossibility of delivering individualized responses. Based on his personal experiences of several years of imprisonment in concentration camps during the Holocaust, Jean Améry in At the Mind's Limit (1980) observed that in the aftermath of mass atrocity "justice could only be hypothetical anyway" (64). In light of these observations, caution is recommended with regard to expectations for transitional justice processes, as resolving these paradoxes and meeting these heightened expectations proves intrinsically difficult. These concerns are certainly applicable to postconflict processes for conflictaffected communities in northern Uganda at large and for male sexual violence survivors in particular, who prior to this book remained largely muted and who continue to be ignored by the country's diverse transitional justice landscape.

\section{CONCLUSION}

Taking these challenges into account, this chapter illuminated how Acholi male sexual violence survivors conceptualize justice and how their views fit into and correspond with contemporary transitional justice developments in northern Uganda. The analysis thereby reveals that Acholi male survivors' justice needs and conceptions are strongly centered around demands for acknowledgment and recognition, as well as immediate physical and material assistance to redress their multiple sexual and gendered harms. Survivors articulated demands to have their silenced and neglected experiences officially acknowledged and legitimized by the institutional perpetrators. These viewpoints accentuate the centrality of recognition for male survivors' sexual and gender harms. In addition, material compensation and physical rehabilitation, as integral elements of reparations, can constitute important avenues for male survivors to achieve harm-responsive and gender-sensitive justice. These two forms of reparations are expected to elevate male survivors back into a position where they are able to work and provide for their families, as they are socially conditioned to as men within hegemonic masculinity constructions. Reparations are therefore seen as responding to the 
violations' impact on survivors' gender identities in reparative and in part even transformative ways.

At the same time, however, the prospects of justice for male survivors in accordance with their needs remain highly elusive and improbable in the contemporary context. The government has not yet acknowledged any responsibility for most of the human rights violations perpetrated by the NRA in the north and certainly not yet for crimes of sexual violence (against women and men). Further, criminal prosecutions on both the national and international level are characterized by numerous legal, judicial, political, and societal barriers, many of which are heavily gendered. Uganda’s transitional justice policy proposes a comprehensive reparations framework, but it maintains strikingly gendered blind spots and lacks consideration of sexual violence (against women and men). These gaps, combined with the fact that the policy has yet to be implemented, negatively affect the possibility for male survivors to have their demands for recognition and reparations met.

In light of these gendered barriers and blind spots of official and formalized transitional justice processes in Uganda, unofficial and noninstitutionalized meanssuch as survivors' groups, localized memorialization initiatives, and nonstate actors' rehabilitative provisions-imply the potential to better address male survivors' gendered harms and thus to achieve a sense of justice. To deliver harmresponsive and gender-sensitive justice for male survivors of sexual violence in northern Uganda as indeed elsewhere, postconflict justice must thus be divorced from the constraints of institutionalism and legalism. To eventually accomplish this, and thus to redress SGBV crimes inclusively and holistically, a survivorcentric approach is needed-as put forward in the concluding chapter. 